Nonlin. Processes Geophys., 25, 537-551, 2018

https://doi.org/10.5194/npg-25-537-2018

(C) Author(s) 2018. This work is distributed under

the Creative Commons Attribution 4.0 License.

\title{
OSSE for a sustainable marine observing network in the Sea of Marmara
}

\author{
Ali Aydoğdu ${ }^{1,2,3}$, Timothy J. Hoar ${ }^{4}$, Tomislava Vukicevic ${ }^{5}$, Jeffrey L. Anderson ${ }^{4}$, Nadia Pinardi ${ }^{6,7}$, Alicia Karspeck ${ }^{4}$, \\ Jonathan Hendricks ${ }^{4}$, Nancy Collins ${ }^{4}$, Francesca Macchia ${ }^{8}$, and Emin Özsoy ${ }^{9}$ \\ ${ }^{1}$ Science and Management of Climate Change, Ca' Foscari University of Venice, Italy \\ ${ }^{2}$ Centro Euro-Mediterraneo sui Cambiamenti Climatici, Bologna, Italy \\ ${ }^{3}$ Nansen Environmental and Remote Sensing Center, Bergen, Norway \\ ${ }^{4}$ National Center for Atmospheric Research, Boulder, Colorado, USA \\ ${ }^{5}$ Office of Water Prediction, National Weather Service NOAA, Tuscaloosa, Alabama, USA \\ ${ }^{6}$ Department of Physics and Astronomy, University of Bologna, Italy \\ ${ }^{7}$ Istituto Nazionale di Geofisica e Vulcanologia, Bologna, Italy \\ ${ }^{8}$ Barcelona Supercomputing Center (BSC), Barcelona, Spain \\ ${ }^{9}$ Eurasia Institute of Earth Sciences, Istanbul Technical University, Turkey
}

Correspondence: Ali Aydoğdu (ali.aydogdu @ nersc.no)

Received: 17 December 2017 - Discussion started: 4 January 2018

Revised: 15 May 2018 - Accepted: 12 June 2018 - Published: 27 July 2018

\begin{abstract}
An observing system simulation experiment (OSSE) is presented in the Sea of Marmara. A highresolution ocean circulation model (FESOM) and an ensemble data assimilation tool (DART) are coupled. The OSSE methodology is used to assess the possible impact of a FerryBox network in the eastern Sea of Marmara. A reference experiment without assimilation is performed. Then, synthetic temperature and salinity observations are assimilated along the track of the ferries in the second experiment. The results suggest that a FerryBox network in the Sea of Marmara has potential to improve the forecasts significantly. The salinity and temperature errors get smaller in the upper layer of the water column. The impact of the assimilation is negligible in the lower layer due to the strong stratification. The circulation in the Sea of Marmara, particularly the Bosphorus outflow, helps to propagate the error reduction towards the western basin where no assimilation is performed. Overall, the proposed FerryBox network can be a good start to designing an optimal sustained marine observing network in the Sea of Marmara for assimilation purposes.
\end{abstract}

\section{Introduction}

The Sea of Marmara is one of the compartments of a water passage known as the Turkish Straits System (hereafter TSS). The TSS connects the Black Sea and the Mediterranean by two narrow straits, namely the Bosphorus and the Dardanelles, along with the Sea of Marmara.

Salty and dense Mediterranean waters and brackish Black Sea waters form a two-layer exchange flow through the TSS. In combination with the complex topography, flow structures on different scales generate a challenging environment for oceanographic studies.

Until recently, building a model to solve the hydrodynamics of the complete TSS was not considered a feasible undertaking due to high computational costs of the required horizontal and vertical resolution enabling the representation of the sharp stratification and the extremely complex topography of the straits and shelf regions, largely differing from those of the larger neighboring basins. However, models with increasing computational capacity to model the whole system have emerged in recent years (Sannino et al., 2017; Gürses et al., 2016; Stanev et al., 2017).

In this study we present, to the best of our knowledge, the first data assimilation experiments performed in the Sea of Marmara. In the region, in situ observations are generally 
scarce and collected by dedicated projects (Ünlüata et al., 1990; Özsoy et al., 2001; Beşiktepe et al., 1994; Tuğrul et al., 2002; Chiggiato et al., 2012) for a limited area and time. Moreover, the spatial resolution and frequency of satellite observations are still not sufficient to monitor the system continuously. For these reasons, a sustainable marine monitoring network is required in the Sea of Marmara. We propose a FerryBox network mounted on existing public transportation infrastructure.

We follow the observing system simulation experiment (OSSE) methodology to achieve our goal. OSSE has been used widely in the atmospheric community for 4 decades to design new observation tools, for error assessment in large models and for parameter estimation (Arnold Jr. and Dey, 1986; Masutani et al., 2010). Atlas (1997) summarizes the criteria established by the atmospheric community to perform credible OSSE. Halliwell Jr. et al. $(2014,2015)$ gave an example of an ocean OSSE in the Gulf of Mexico by following those criteria. Aydoğdu et al. (2016) studied a fisheryobserving system in the Adriatic Sea, taking the same criteria into account.

This paper is organized as follows: in the next section, the main characteristics of the TSS relevant to this study are summarized. In Sect. 3, the model and data assimilation scheme that we used are documented. Section 4 is devoted to the OSSE design. The nature run and forward model are introduced. FerryBox network design is also detailed and the methodology for impact assessment is outlined. The results are discussed in Sect. 5. The summary and conclusions are presented in the last section.

\section{Overview of the Turkish Straits System}

The Sea of Marmara with the Bosphorus and the Dardanelles straits constitute the Turkish Straits System, which connects the Black Sea and the Mediterranean. The exchange of contrasting water masses forms a highly stratified water column structure throughout the system with a pycnocline around $20 \mathrm{~m}$ depth. The brackish surface water of the Black Sea flows towards the Mediterranean in the upper layer and the salty and dense Mediterranean Sea water occupies the lower layer of the water column (Ünlüata et al., 1990). In addition to the strong stratification, the complex topography of the two narrow straits and an internal sea with shallow shelves and deep depressions presents a unique and challenging environment for oceanographic studies.

The Bosphorus is an elongated narrow strait connecting the Black Sea and the Sea of Marmara. The upper layer flow is dominated by the Black Sea water, with salinity of about $18 \mathrm{psu}$. The lower layer water originates in the Mediterranean and reaches the Black Sea with a salinity of about $37 \mathrm{psu}$. The interface depth between the two layers is mainly determined by the salinity gradient. In summer, a three-layer temperature structure appears. A warm upper layer due to the atmospheric heat flux overlays a cold intermediate layer that propagates from the Black Sea. Warmer Mediterranean water constitutes the bottom layer (Altiok et al., 2012). The constriction in the midsection and the sill in the southern section of the strait apply a hydraulic control on the flow and produce a surface jet at the Sea of Marmara exit (Sözer and Özsoy, 2017). The velocity of the Bosphorus jet can exceed $2 \mathrm{~m} \mathrm{~s}^{-1}$ (Jarosz et al., 2011). Therefore, the jet is one of the key factors influencing the dynamics of the Sea of Marmara. It enhances the mixing by entraining lower layer water (Ünlüata et al., 1990), energizes the Sea of Marmara circulation in the eastern basin (Beşiktepe et al., 1994) and produces mesoscale eddies due to the potential vorticity balance (Sannino et al., 2017).

The wind is another important factor influencing the dynamics of the Sea of Marmara. Many strong cyclones pass over the Sea of Marmara, especially in winter (Book et al., 2014). Northeasterly winds dominate the atmospheric circulation throughout the year.

The third important dynamical constituent is the densitydriven baroclinic flow in the lower layer (Hüsrevoğlu, 1998). The velocity of the flow in the lower layer can reach $1 \mathrm{~m} \mathrm{~s}^{-1}$ (Jarosz et al., 2012).

The high complexity of the system requires models that simultaneously solve the whole system in its smallest resolved details and optimally represent multiple scales of interest.

\section{Ensemble modeling and data assimilation in the TSS}

The ocean model used in this study is the Finite Element Seaice Ocean Model (FESOM). FESOM is an unstructured mesh ocean model using finite element methods to solve the hydrostatic primitive equations with the Boussinesq approximation (Danilov et al., 2004; Wang et al., 2008). Gürses et al. (2016) applied FESOM to the TSS and performed realistic simulations of the complete system using atmospheric forcing. The TSS model domain extends zonally from 22.5 to $33^{\circ} \mathrm{E}$ and meridionally from 38.7 to $43^{\circ} \mathrm{N}$. The mesh resolution is as fine as $65 \mathrm{~m}$ in the Bosphorus and $150 \mathrm{~m}$ in the Dardanelles. In the Sea of Marmara, the resolution is always finer than $1.6 \mathrm{~km}$ and is not coarser than $5 \mathrm{~km}$ in the Black Sea and the Aegean Sea. The water column is discretized by 110 vertical $z$ levels. Vertical resolution is $1 \mathrm{~m}$ in the first $50 \mathrm{~m}$ depth and increases to $65 \mathrm{~m}$ at the bottom boundary layer in the deepest part of the model domain. The mesh has 70240 nodes at the surface layer and more than 3 million nodes for the 3-D state variables i.e., temperature, salinity, zonal and meridional velocity.

Aydoğdu (2017) performed interannual simulations using a similar model setup. Two 6-year simulations using different surface salinity boundary conditions have been completed and evaluated. It is shown that the model is able to simulate main characteristics of the system qualitatively. It simulates the two-layer structure of the TSS, successfully. Moreover, dynamical properties such as sea level difference be- 
tween different compartments and dynamics related to highfrequency atmospheric events are well captured. However, the error growth in temperature and salinity throughout the simulation is also demonstrated, which motivates the need for data assimilation in the TSS.

In this study FESOM has been coupled with an ensemblebased data assimilation framework, Data Assimilation Research Testbed (DART). DART is an open-source community facility developed at NCAR (Anderson et al., 2009) that provides data assimilation tools to work with either loworder or high-order models for different research activities (Raeder et al., 2012; Karspeck et al., 2013; Schwartz et al., 2015; Hoteit et al., 2013).

DART includes several different stochastic and deterministic ensemble Kalman filtering algorithms. In this study, we use the ensemble adjustment Kalman filter (EAKF) as described in Anderson (2001). The EAKF is a deterministic ensemble Kalman filter, where the observations are not perturbed randomly before they are assimilated. One of the main advantages of the EAKF for our application is that it preserves the prior covariance distribution during resampling, which is not the case for the ensemble filters such as kernel or Gaussian resampling filters. The ensemble covariance is used to quantify the relation between pairs of state variables or an observation and a state variable in the linear Gaussian context of the ensemble Kalman filter. In other words, it is the statistical representation of the prior constraints (dynamical balances) generated by the model. For a linear model, a sufficiently large ensemble would be able to represent all the balances. However, our model is nonlinear and cost forces us to use a small ensemble. This means that the ensemble sample covariances do not exactly represent the dynamical balances. The ensemble filter algorithm and inflation we use are designed to maintain the prior ensemble covariance as much as possible. Moreover, localization is effective in reducing forecast root mean square error (RMSE) compared to observations, given the errors in the sample covariances. However, it disrupts the prior sample covariance, so can result in reduced dynamical balance. In the TSS, where different dynamics compete and generate circulation structures at various scales, the prior distribution is crucial for maintaining the dynamical balances among different scales, which justifies the choice of the EAKF. In addition, analysis covariances are updated in every assimilation cycle, which is important to sustain the high-frequency variability of the system.

One of the main issues to take into consideration in ensemble data assimilation is the filter divergence. It can result from insufficient ensemble variance, which leads to assigning more weight to the prior information that in turn may cause rejection of information from observations. As a result, the analysis departs from the observations (Anderson, 2001). There are techniques to prevent filter divergence such as inflating the covariances (Anderson and Anderson, 1999). In the standard DART, inflation of the prior ensemble leads to multiplying the prior covariances by a constant slightly larger than 1. Instead of DART's multiplicative covariance inflation, we have applied random perturbations to the background vertical diffusivity for each ensemble member since one of the main sources of error in the model is the vertical mixing and the position of the interface between the upper and lower layers. The background vertical diffusivity $\kappa_{\mathrm{v}_{0}}$, which is implicitly represented in the $\kappa_{\mathrm{V}}$ of the tracer equations, is randomly perturbed all over the domain every time step by fitting a Gaussian distribution, with a mean of 0 and a standard deviation of $5 \%$ of the $\kappa_{\mathrm{v}_{0}}$. We note that $\kappa_{\mathrm{v}_{0}}$ is approximately 2 orders of magnitude smaller than the spatially and temporally varying $\kappa_{\mathrm{v}}$.

Houtekamer and Mitchell (1998) show that spurious correlations in the prior information can be avoided by using large ensembles. Since it is computationally expensive to use large ensembles in large geophysical models, they proposed a spatial localization technique to overcome spurious small correlations associated with remote observations. The impact of an observation on state variables is reduced as a function of distance from the observation, with impact going to zero at a finite cutoff value. In DART, the cutoff value can be set as a constant value in radians. The localization function is the fifth-order piecewise continuous function, compactly supported as presented in Gaspari and Cohn (1999). The horizontal cutoff radius, which is the half-width of the GaspariCohn kernel, is used to deal with the high spatial variability of the water masses along the TSS. Moreover, the water column in the TSS is strongly stratified in the vertical. Therefore, vertical localization is also applied to update the state in the upper layer of the water column, with less impact in the lower layer. As a result, the localization is an ellipsoidal volume centered on the observation being assimilated, with a horizontal radius of two cutoff values and vertical radius of two cutoff values normalized by a factor. This approach is chosen to avoid problems such as the breaking of the stratification during the integration.

For interfacing FESOM and DART, a forward operator that maps model state vector into observation space, characterized by a type of physical quantity, georeferenced location and time were defined. For the FerryBox type of observations we used a simple, but theoretically justifiable nearestneighbor mapping. Specifically, for each discrete observation value the forward operator first finds the closest horizontal grid point in the state vector and then the closest vertical location.

The details of the FESOM-DART coupling are shown schematically in Fig. 1. The interface to DART requires two model-specific routines that convert the model restart files to DART state vectors and vice versa. For the model-to-DART step the state vector is provided from each ensemble member. The updated state vectors are then converted to the model restart files as an initial ensemble for the next assimilation cycle within which FESOM is applied to integrate the model state forward to the next analysis time. This process is repeated until the experiment finishes. 


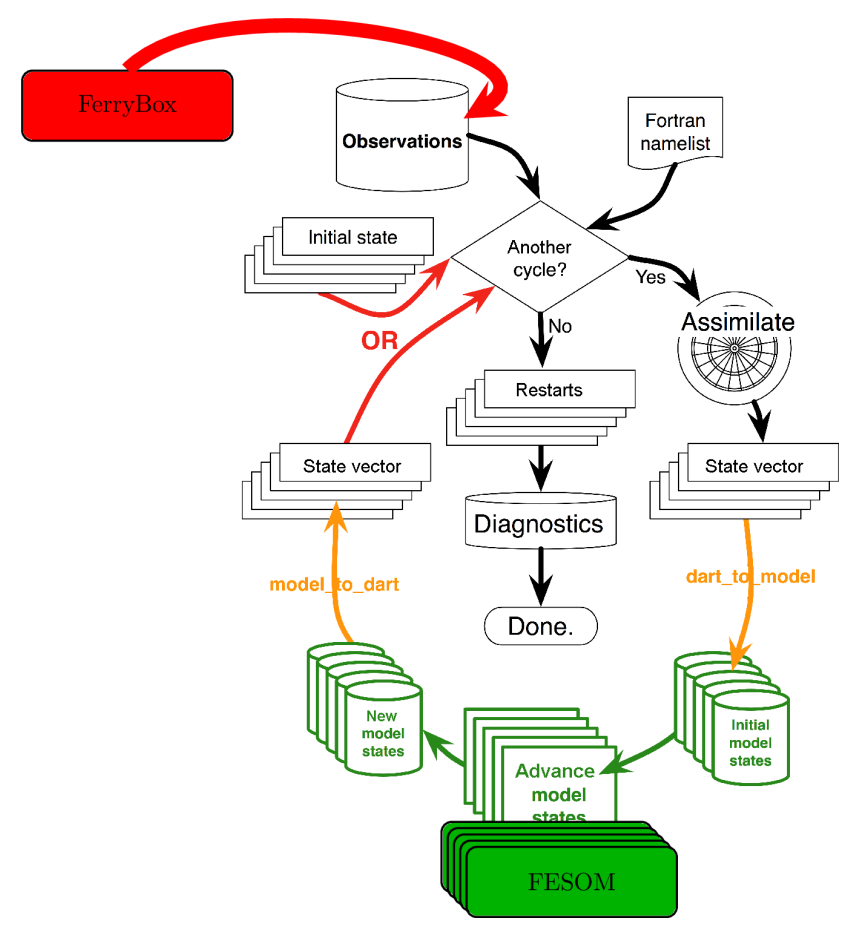

Figure 1. Flow of FESOM-DART system. Reproduced after Anderson et al. (2009) with modifications for the TSS application.

\section{Design of the OSSE}

The OSSE methodology used is shown schematically in Fig. 2. A proposed FerryBox network was assumed to be in the eastern Sea of Marmara using the existing transportation infrastructure. Therefore, we were able to the simulate the observations from the FerryBox network by tracking the ferry lines in the Sea of Marmara. The impact assessment of this network was performed using the FESOM-DART ensemble data assimilation system.

\subsection{The nature run and forward model}

The OSSE methodology requires a representation of a reference true atmosphere or ocean that is called the nature run (NR). The NR is used for generating the synthetic observations to assimilate and for assessing the quality of the assimilation. For a fully objective OSSE the NR should be created using a simulation from a different model than the forward model (FM) used in the assimilation in an attempt to simulate the inevitable model errors.

In the current study the fraternal twin method was used, where the NR and FM are based on the two different configurations of the same model. The difference between the NR and the FM configurations is the surface salinity boundary condition, where the former employed the relaxation boundary condition for the sea surface salinity, whereas the latter uses the mixed salinity boundary condition (Huang, 1993, see also Appendix A).
This approach was chosen because FESOM in the Sea of Marmara is sensitive to equally plausible salinity boundary conditions. This was demonstrated through long-term simulations using both configurations, which were validated with the actual in situ observations (Aydoğdu, 2017). The simulations were performed for period 1 January 2008 to 31 December 2013. It is demonstrated that they deviate from each other but both are still realistic during the OSSE period, which is 1-8 January 2009. The output of the NR was saved hourly during the OSSE period to generate synthetic observations.

The ensemble consists of 30 members. An initial ensemble is produced for 1 January 2009 as schematized in Fig. 3. The 5-year means of the temperature and salinity for January are computed from the multiyear simulation. Then, the deviations of each day between 2 and 31 January 2009 from the interannual mean are calculated. Finally, these deviations are added to the temperature and salinity fields of 1 January 2009 to provide an initial perturbation for each ensemble member. Figure 4 shows the variance of the initial ensemble for salinity and temperature for the depths 5 and $20 \mathrm{~m}$. The horizontal distributions of the variance are similar for both variables. The variance is larger in the exits of the straits. In particular, the spread at the Bosphorus exit for the upper layer down to $15 \mathrm{~m}$ is larger due to the variability in the outflow. Correspondingly, the Dardanelles inflow to the Sea of Marmara increases the variance in the lower layer. Such a distribution of initial variance in the Sea of Marmara is appropriate to initialize the experiments since the assimilation of synthetic observations is performed in the impact area of the Bosphorus outflow where the ensemble spread can be diminished by the assimilation.

\subsection{The eastern Sea of Marmara FerryBox network design}

The Marmara region has the highest urban population in Turkey. It includes the metropolitan city of Istanbul, which is divided into two by the Bosphorus and surrounded by the Black Sea in the north and the Sea of Marmara in the south. As a consequence, a network of ferries is an essential means of transportation. The main hub for the ferries is Istanbul, which is connected to the other cities around the Sea of Marmara by several ferries (Fig. 5a).

In the Sea of Marmara, it is not easy to deploy, for instance, argo floats or gliders close to the surface since there is heavy ship traffic. However, the infrastructure for a FerryBox network is already available. The ferry lines in the Sea of Marmara cover most of the eastern basin, including the Sea of Marmara exit of the Bosphorus. Using the ferry network as a monitoring system would be an efficient way to build a sustainable ocean-observing network in the Sea of Marmara.

Some existing state-of-the-art FerryBox networks are discussed by Petersen (2014). Usage has increased since the European network for FerryBox measurements project 


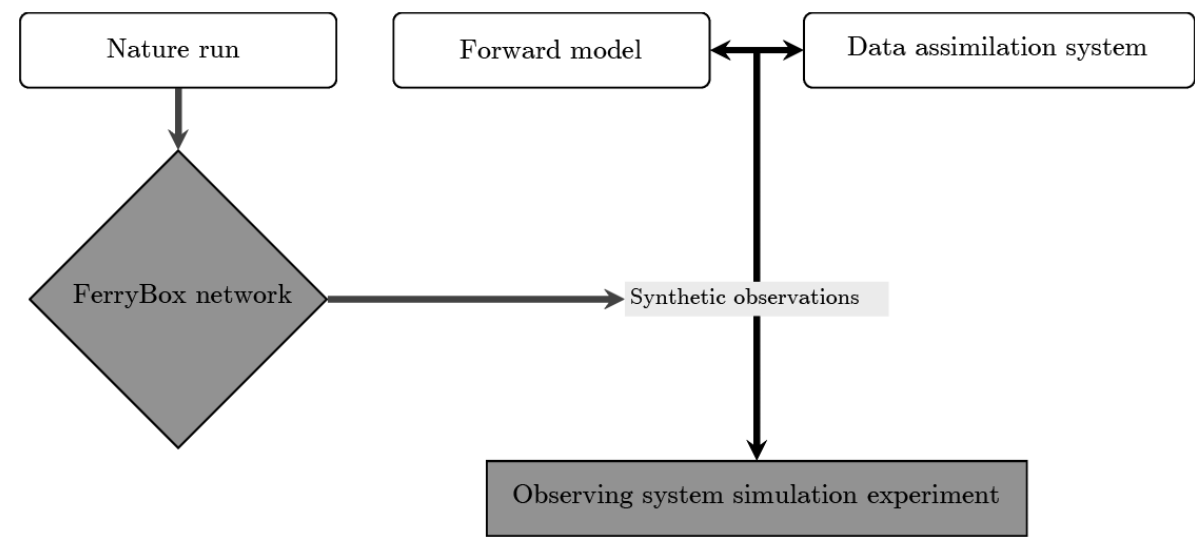

Figure 2. OSSE methodology applied in the Turkish Straits System. The forward model (FM) is a different configuration of the model setup used for the nature run (NR) as detailed in the text.

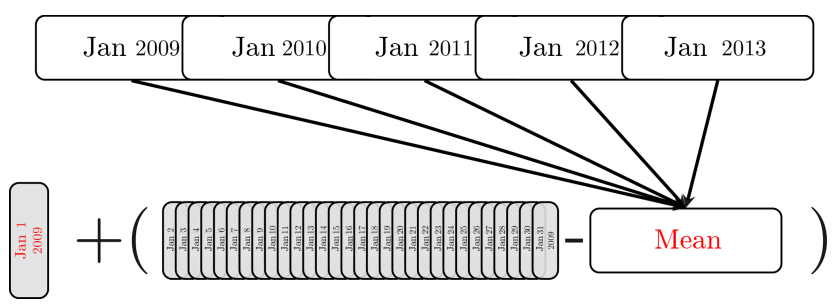

Figure 3. Schematic representation of the methodology used to generate the initial ensemble. MEAN is the January averages over 5 years between 2009 and 2013 .

(http://www.ferrybox.org, last access: June 2018), especially in the northern European seas. In the Mediterranean, there is a FerryBox system between Piraeus and Heraklion (Korres et al., 2014) operated by Hellenic Centre for Marine Research (HCMR). A FerryBox mainly includes temperature, salinity, turbidity and chlorophyll $a$ fluorescence sensors, as well as a GPS receiver for measuring position. Oxygen, $\mathrm{pH}$, $p \mathrm{CO}_{2}$ or algal groups as well as air pressure, air temperature and wind sensors can also be installed (Petersen, 2014). The FerryBox observations can be used for analyzing the state of the ocean (Seppälä et al., 2007) and comparison with other instruments (Sørensen et al., 2007) and can also be assimilated to improve the state of the ocean models (Grayek et al., 2011).

The sampling rate of the data can vary between systems. The data used in Grayek et al. (2011) are sampled at $10 \mathrm{~s}$ intervals. For our OSSE, we use a sampling rate of $1 \mathrm{~min}$ following Korres et al. (2014). The synthetic observations are obtained from hourly NR outputs at varying spatial locations so as to remain within 1 min time intervals along the track of the ferries. The depth of the sampling is set to $5 \mathrm{~m}$, an average depth given by Grayek et al. (2011). A random error, sampled by a Gaussian distribution around zero mean and standard deviation of $0.1{ }^{\circ} \mathrm{C}$ for temperature and $0.04 \mathrm{psu}$ for salinity, is added to each synthetic observation following
Aydoğdu et al. (2016) in order to simulate realistic measurements, taking the instrumental error into account. These synthetic observations are the same for each ensemble member; i.e., the Kalman filtering is not stochastic in which observations are perturbed. Moreover, observational error matrices in the Kalman gain are chosen to be uncorrelated and constant diagonal, with $0.5^{\circ} \mathrm{C}$ and $0.25 \mathrm{psu}$ for temperature and salinity, respectively, as proposed by Grayek et al. (2011) while considering other sources of error such as representativeness.

Three different ferry routes are chosen from the map in Fig. 5a, and their tracks are approximated by observing from the real-time Marine Traffic (https://www.marinetraffic.com, last access: June 2018) application (Fig. 5b). The longest duration for a cruise in the eastern Sea of Marmara is about $3.5 \mathrm{~h}$ between Ambarlı and Topçular (Table 1). Another transect used here is YeniKap1-Yalova, which takes about $75 \mathrm{~min}$ and has cruises every $2 \mathrm{~h}$ from each port. This route directly crosses the Bosphorus outflow and has the highest number of cruises a day. Therefore, we include six ferries in various periods of the day for YeniKapi-Yalova transect. The last transect chosen is Yenikapı-Bandırma, which crosses the Sea of Marmara from north to south. The navigation on this line takes about $2.5 \mathrm{~h}$. This transect is the only one that has direct impact in the southern basin. The resulting synthetic temperature and salinity observations sampled from the NR for the first day are shown in Fig. 6.

\subsection{Experiments}

Two experiments are performed as an initial evaluation for the data assimilation studies in the Sea of Marmara (Table 2). The first experiment FB001 is a reference experiment without assimilation. It is used to evaluate the errors when the synthetic observations are not assimilated. In the second experiment, FB002, all the synthetic observations are assimilated in the corresponding assimilation window. A $6 \mathrm{~h}$ width is chosen for each assimilation window, since the area is un- 
Table 1. The unidirectional ferry tracks used in this study. The locations, distance between the ports, speed of the ferries, duration of the cruise and time of departure from each port are listed.

\begin{tabular}{|c|c|c|c|c|c|}
\hline Route & Location & Distance & Speed & Duration & Departure time (UTC) \\
\hline Yenikap1 & $41.002^{\circ} \mathrm{N}, 28.956^{\circ} \mathrm{E}$ & \multirow{3}{*}{46.2 km (28.7 mi.) } & \multirow{3}{*}{$23 \mathrm{kn}$} & \multirow{3}{*}{$75 \mathrm{~min}$} & $09: 45,15: 45,21: 45$ \\
\hline- & & & & & \\
\hline Yalova & $40.661^{\circ} \mathrm{N}, 29.274^{\circ} \mathrm{E}$ & & & & $07: 15,13: 45,19: 45$ \\
\hline Yenikapı & $41.002^{\circ} \mathrm{N}, 28.956^{\circ} \mathrm{E}$ & \multirow{3}{*}{$110.0 \mathrm{~km}(68.5 \mathrm{mi})}$. & \multirow{3}{*}{$27 \mathrm{kn}$} & \multirow{3}{*}{$150 \min$} & $07: 30$ \\
\hline- & & & & & \\
\hline Bandirma & $40.354^{\circ} \mathrm{N}, 27.967^{\circ} \mathrm{E}$ & & & & $18: 30$ \\
\hline Ambarlı & $40.966^{\circ} \mathrm{N}, 28.676^{\circ} \mathrm{E}$ & \multirow{3}{*}{$70.0 \mathrm{~km}$ (43.2 mi.) } & \multirow{3}{*}{$12 \mathrm{kn}$} & \multirow{3}{*}{$210 \min$} & $20: 00$ \\
\hline- & & & & & \\
\hline Topçular & $40.690^{\circ} \mathrm{N}, 29.434^{\circ} \mathrm{E}$ & & & & $16: 00$ \\
\hline
\end{tabular}

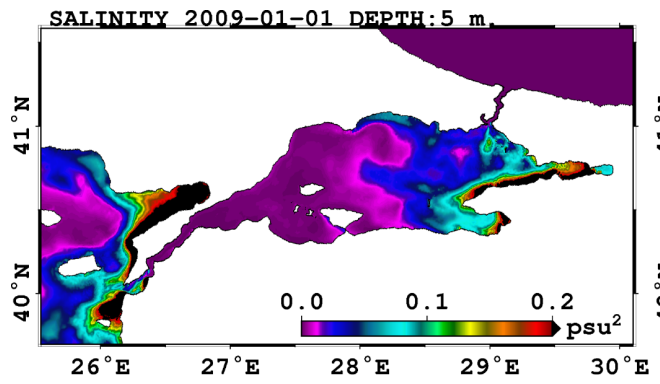

(a) Salinity at $5 \mathrm{~m}$

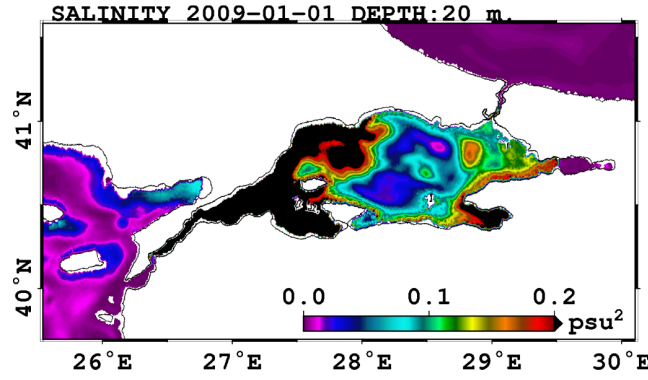

(c) Salinity at $20 \mathrm{~m}$

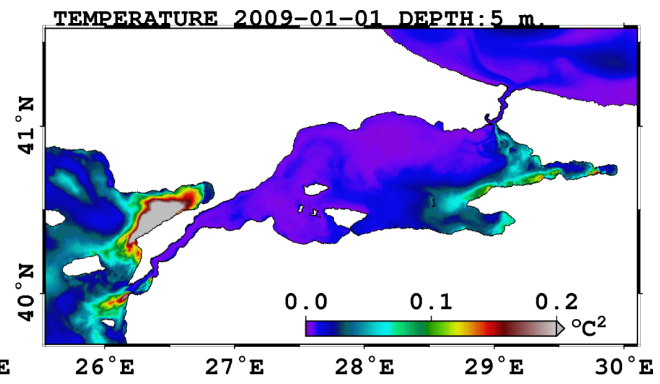

(b) Temperature at $5 \mathrm{~m}$

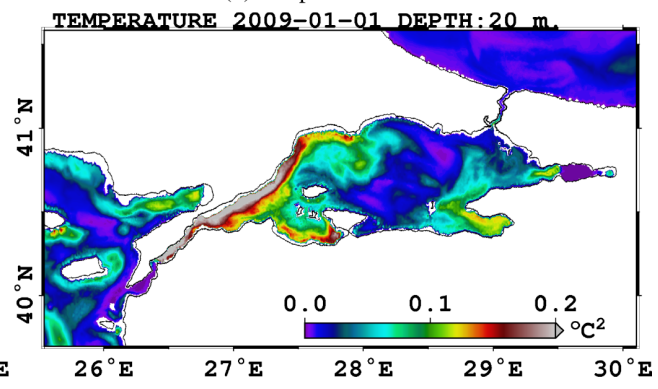

(d) Temperature at $20 \mathrm{~m}$

Figure 4. Salinity $(\mathbf{a}, \mathbf{c})$ and temperature $(\mathbf{b}, \mathbf{d})$ variance of the initial ensemble at $5 \mathrm{~m}(\mathbf{a}, \mathbf{b})$ and $20 \mathrm{~m}(\mathbf{c}, \mathbf{d})$ depth on 1 January 2009 at 00:00 UTC.

Table 2. Summary of the OSSEs. Start and end date of both experiments are the same. There is no assimilation in FB001 whereas all the data are assimilated in FB002. Assimilation cycle is $6 \mathrm{~h}$ for FB002.

\begin{tabular}{llllll}
\hline & Start date & End date & Assimilation & A. cycle & Evaluation \\
\hline FB001 & 1 Jan 2009 00:00 & 8 Jan 2009 00:00 & None & n/a & Yes \\
FB002 & 1 Jan 2009 00:00 & 8 Jan 2009 00:00 & All & 6h & Yes \\
\hline
\end{tabular}

n/a: not applicable

der the influence of the Bosphorus jet, which may develop high-frequency variability in the water mass structure and circulation at the upper layer, especially during severe storms and atmospheric cyclone passages.
The horizontal cutoff radius is set to $6.36 \mathrm{~km}$ and the vertical cutoff radius is considered as $15 \mathrm{~m}$ centered on the observation location. The mean temperature and salinity increments after the first and third assimilation cycle are shown in Fig. 7a and b, respectively. As can be seen from the temper- 


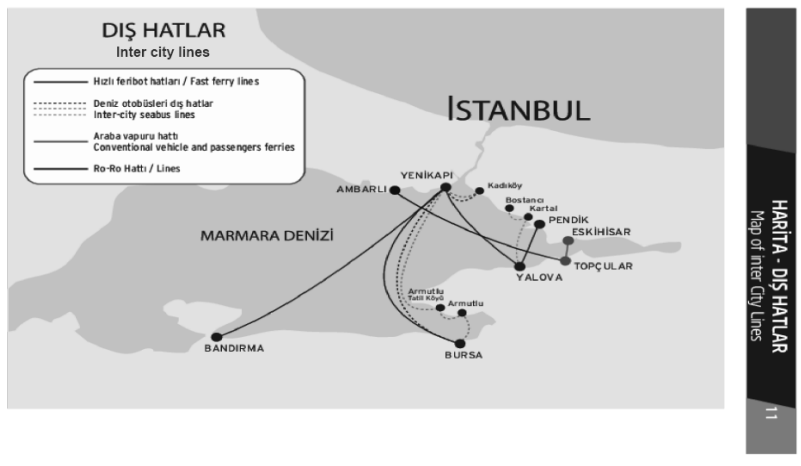

(a)

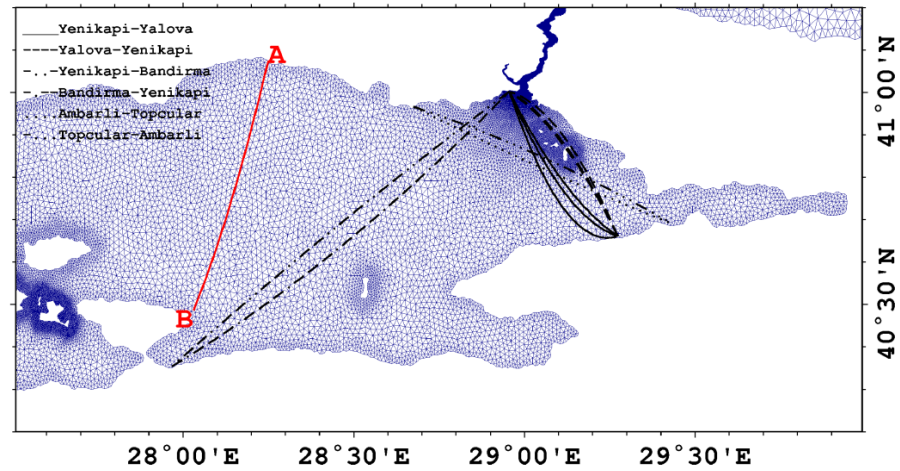

(b)

Figure 5. (a) The routes of the intercity ferry lines from Istanbul and to Istanbul suggested by the operating company IDO (http://www.ido. com.tr, last access: June 2018). (b) Approximate unidirectional ferry tracks. The legend shows the direction of the ferries. The section A-B is used only for impact assessment against the NR. Triangular mesh of the model is underlaid.

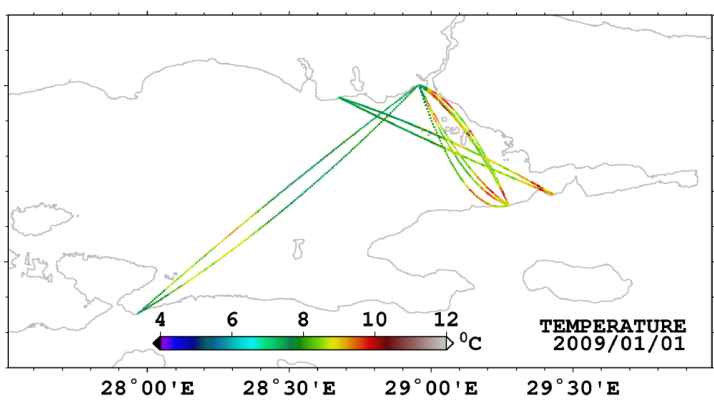

(a)

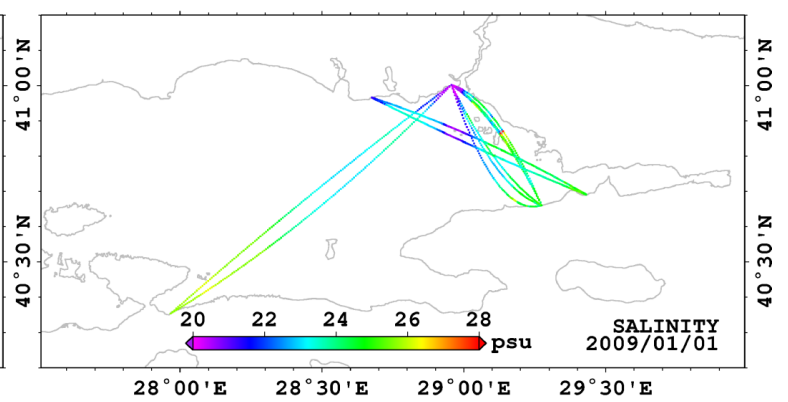

(b)

Figure 6. Synthetic (a) temperature and (b) salinity observations on 1 January 2009 sampled from the NR.

ature corrections after the first cycle, the whole track of the Yenikapı-Bandirma route is not assimilated at the same time since the southern section of the data is not in the current assimilation window. Moreover, the updates on the salinity fields are smaller around $20 \mathrm{~m}$ (Fig. 7b), compared to the upper layers (not shown) closer to the observation locations.

\subsection{Methodology for impact assessment}

The DART offers tools to have the control of the data without any difficulty. Each type of observation can either be assimilated or withheld to evaluate the resulting analyses. DART also provides a rudimentary quality control capability that can reject observations that are too different from the ensemble mean prior estimate. Synthetic observations are not used in the assimilation (rejected) if $x_{b}-y>T E\left(x_{b}-y\right)$. Here, $y$ is the observation and $x_{b}$ is the corresponding prior mean of the ensemble of forward operators. The expected value, $E$, is computed as follows:

$E\left(x_{b}-y\right)=\sqrt{\sigma_{x_{b}}^{2}+\sigma_{y}^{2}}$, where $\sigma$ stands for the standard deviation. $T$ is chosen as 3 for both temperature and salinity in these experiments, considering the real model errors reported by Aydoğdu (2017).

The first diagnostic we use to assess the impact of the observations is the root mean square of innovations, which are the root mean square of the difference between the prior and observation. We also use horizontal maps of the innovations to determine the spatial distribution of error.

The OSSE methodology enables various ways of evaluating the analysis since the NR is assumed to be the true state of the system. We exploit this assumption to compare the experiments with the NR to understand the impact of assimilation better.

One diagnostic we use in this sense is the comparison between the NR and ensemble mean in the vertical. Although we do not assimilate any data below $5 \mathrm{~m}$ and we limit the radius for vertical updates, it is important to assess the vertical distribution of the errors given the strongly stratified water column in the Sea of Marmara. For this purpose, we compute the difference between prior ensemble mean and NR along the transect A-B (see Fig. 5) in the first $50 \mathrm{~m}$ depth. 


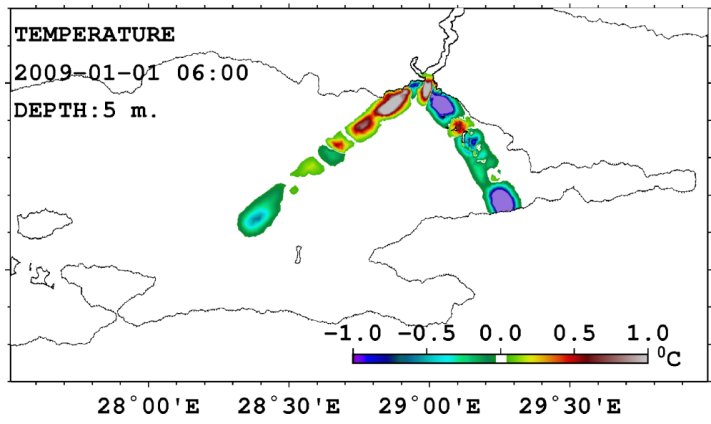

(a)

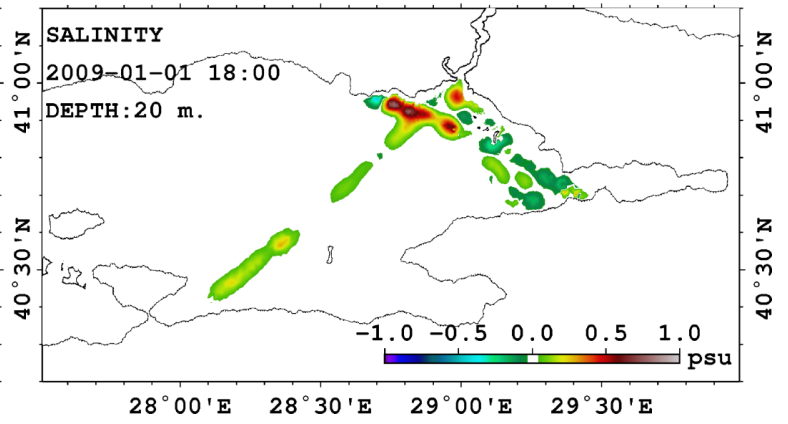

(b)

Figure 7. Mean increments after assimilation for (a) temperature at 1 January 2009 at 06:00 UTC at $5 \mathrm{~m}$ depth and (b) salinity at 1 January 2009 18:00 UTC at $20 \mathrm{~m}$ depth.

The second diagnostic is the root mean square (RMS) of difference between the prior ensemble mean and the NR computed in the first $10 \mathrm{~m}$ of the water column for the whole basin. The propagation of the error reduction can be traced from the spatial maps of this diagnostic.

\section{Results}

Figure 8 shows the time evolution of prior RMS of innovations, ensemble spread and total spread for temperature and salinity. The RMS of salinity innovations continuously grows in FB001. It fluctuates around 2 psu and reaches 2.4 psu at the end of sixth day. In FB002, assimilation of the observations decreases the RMS of innovations significantly. The RMS of innovations is generally below $1.2 \mathrm{psu}$. Although there is an increase of error in the first 2 days, a gradual reduction takes place in the following days. The RMS of temperature innovations behaves similarly to that of salinity after the second day. The error grows in FB001 even though the trend is not as obvious as in salinity errors of the same experiment. The analysis is improved at the end of experiment FB002 compared to FB001. The range of errors is comparable to the real model errors with respect to in situ observations, as demonstrated by Aydoğdu (2017). Another important result is that the ensemble still has spread comparable to the RMSEs at the end of the experiments (larger in FB001). In other words, the ensemble did not collapse after a week of assimilation. We recall that the ensemble spread is maintained by perturbing the background vertical diffusivity. The method seems promising at least for a week-long period.

As discussed in Sect. 4.4, the data are subjected to a quality control before assimilation. Figure $8 \mathrm{c}$ and d show the number of available observations ( $\left.N_{\text {poss }}\right)$, number of used observations $\left(N_{\text {used }}\right)$ and number of outlier observations $\left(N_{\text {out }}\right)$. The decrease in the number of outlier observations in FB002 also points out an improvement in the regions in which the innovations are larger, as can be deduced from Fig. 9.
On the last day of experiments (Fig. 9), the salinity innovations are better almost everywhere in FB002 compared to FB001. There is a significant reduction in errors in the northern basin. Assimilation decreases the number of outlier salinity observations, especially on the route between Yenikap1 and Yalova. Moreover, innovations are also improved to a lesser extent in the southern basin where fewer observations are assimilated. The number of outlier temperature observations is very small in both experiments. Overall, the assimilation of temperature and salinity observations in the selected transects notably helps to correct the water column above the pycnocline.

The improvement of the analysis is also noticed in remote areas such as the A-B transect in the central basin (see Fig. 5). Figure 10 shows the difference between the truth and prior state down to $50 \mathrm{~m}$ depth along the A-B transect after the last assimilation cycle. Comparison of salinity differences between FB001 and FB002 reveals the improvement in the northern section down to $15 \mathrm{~m}$ depth. The southern part away from the coast also becomes better. The middle of the transect still has large discrepancies in both experiments at the end of 7 days. The correction in the remote area suggests a mechanism related to the outflow of the Bosphorus and the surface circulation of the Sea of Marmara. The water masses that are corrected by assimilation in the eastern basin are pushed towards the west and reduce the error.

Figure 11 depicts the RMS of the difference between NR and prior ensemble mean salinity at the first $10 \mathrm{~m}$ depth. It clearly supports the mechanism suggested above. The distribution of RMS of differences in the nonassimilation case shows that the Bosphorus outflow also has some capability to reduce the difference since the Black Sea water masses govern the upper layer of the Sea of Marmara (Fig. 11a and c). These two snapshots from the fifth and the last day of FB001 show the error reduction in some regions due to the dynamics. Therefore, the conclusion that the improvement is due to the assimilation is not straightforward. However, comparison of the FB001 and FB002 reveals the role of the assimilation 


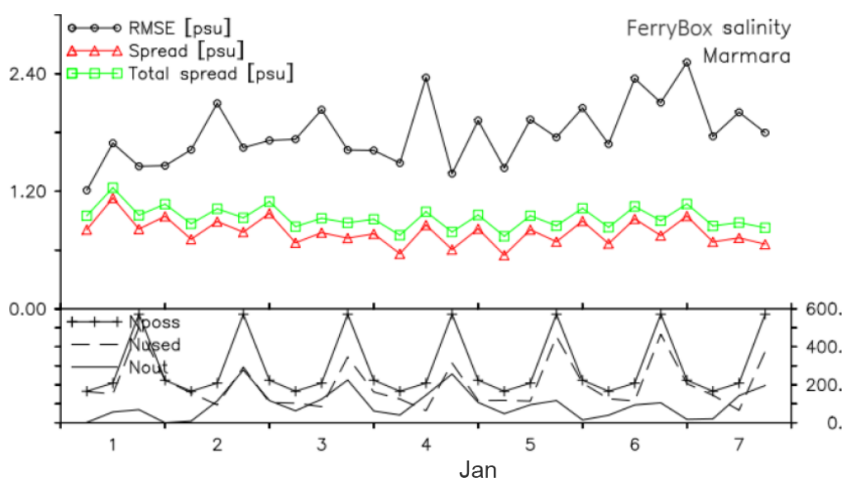

(a)

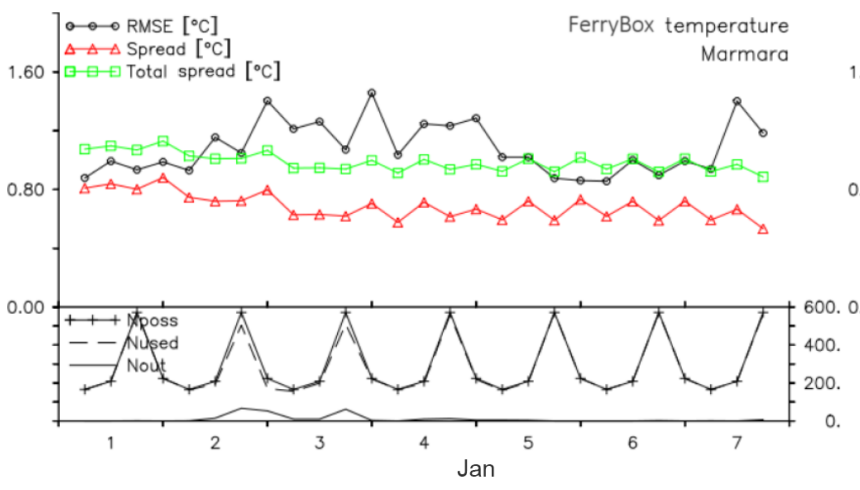

(c)

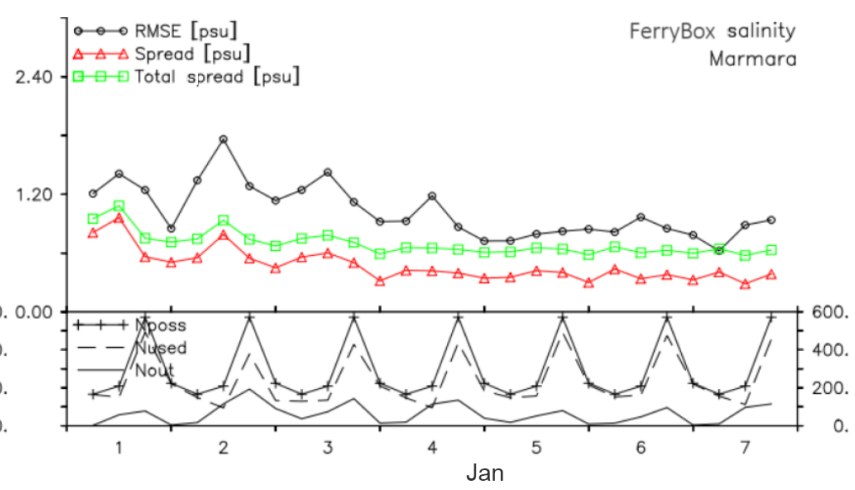

(b)

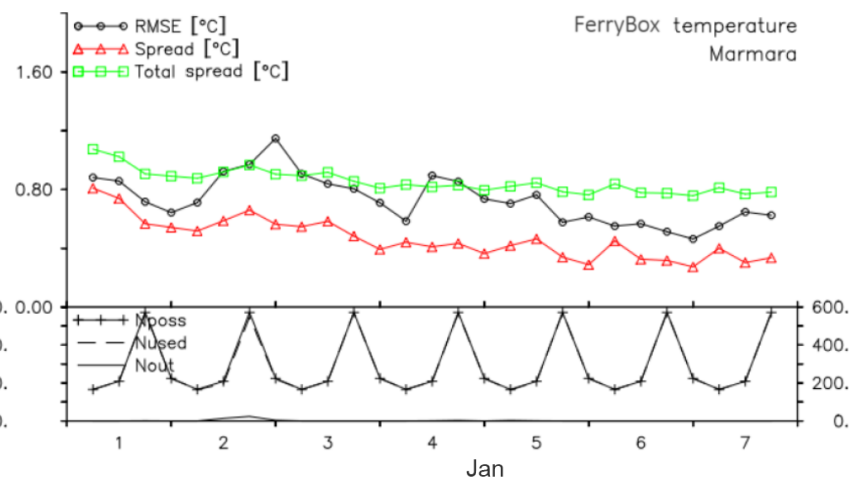

(d)

Figure 8. Time series of prior RMS of innovations, spread, and total spread of salinity (a, b) and temperature (c, d) for FB001 (a, c) and FB002 (b, d). The statistics are computed in the location of the observations used in the corresponding assimilation cycle. The spread is the square root of the variance. Total spread is the square root of the observational error added to the variance. Vertical axis shows the range of each statistics indicated in the legend. Bottom panel of each figure shows the number of available observations $\left(N_{\text {poss }}\right)$ in each assimilation cycle. For the assimilation experiment, FB002, $N_{\text {used }}$ and $N_{\text {out }}$ show the number of assimilated observations and outliers, respectively. For the experiment without assimilation, FB001, they are the number of observations that would be assimilated or rejected, respectively, in that specific assimilation cycle if assimilation was performed.

of ferry tracks on the error reduction, clearly. On the fifth day, lower RMS of differences in FB002 (Fig. 11b) extends towards the easternmost part of the basin, which is absent in FB001 (Fig. 11a). The westwards propagation is more pronounced on the last day in FB002 (Fig. 11d) compared to FB001 (Fig. 11c). The central basin has lower errors almost everywhere in the north-south orientation, including the AB transect shown before.

Temperature fields are already closer to the NR on the fifth day even in the western basin (Fig. 12). After 7 days of assimilation, the temperature error in the Bosphorus plume is significantly reduced. The southern and central basin has improvements as much as $0.5^{\circ} \mathrm{C}$ locally.

Finally, Fig. 13 compares FB001 and FB002 in terms of salinity fields overlaid with corresponding circulation at $5 \mathrm{~m}$ depth on 7 January 2009 at 00:00 UTC. The salinity differs significantly between the two experiments, especially along the southeastern coast, while there is very little change in both qualitative and quantitative terms in the horizontal cir- culation, namely the current speed and direction, in the affected region that can be attributed to assimilation. The effect of assimilation is more pronounced in terms of the property fields, which alternatively indicates changes in stratification and vertical mixing along the southern coast. This can also be seen in the comparison of the experiments (Fig. 13) with the nature run (Fig. A1b), which shows that salinity in the FB002 is closer to the nature run than FB001 where the synthetic observations are assimilated. However, circulation is always more intense in the nature run compared to both experiments but both have a similar circulation pattern.

\section{Summary and discussion}

We have described data assimilation experiments performed in the Sea of Marmara. The main characteristics of the TSS have been summarized. For the study, a general ocean circulation model, FESOM, and an ensemble data assimilation 


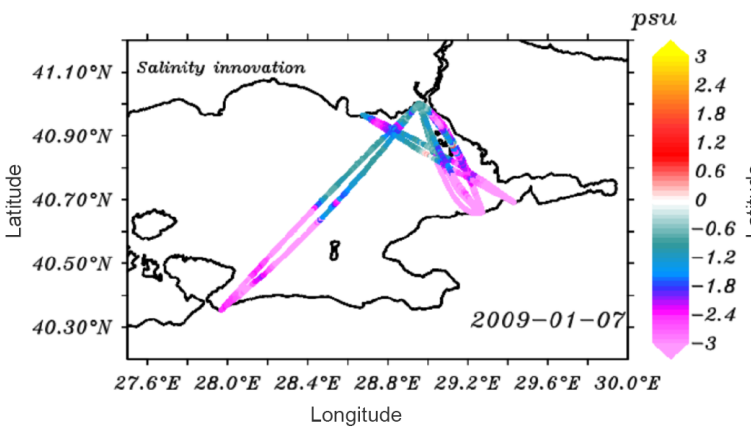

(a)

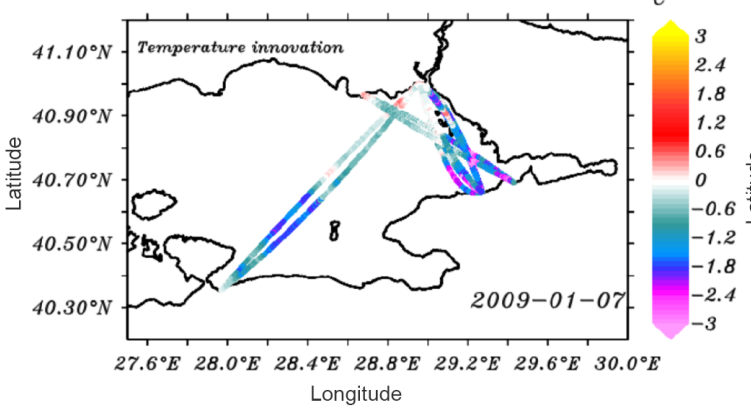

(c)

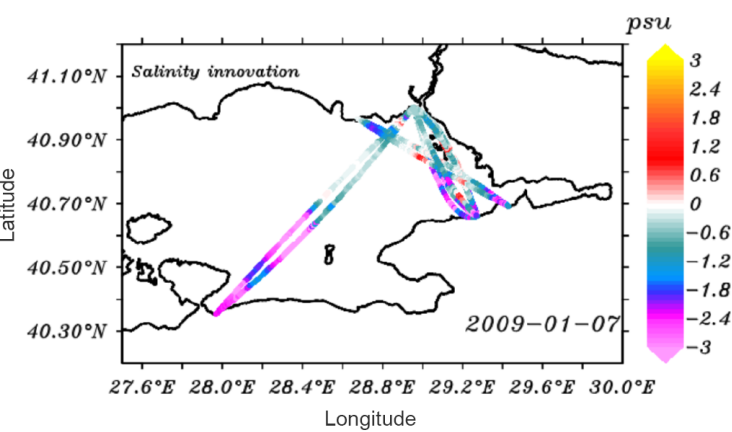

(b)

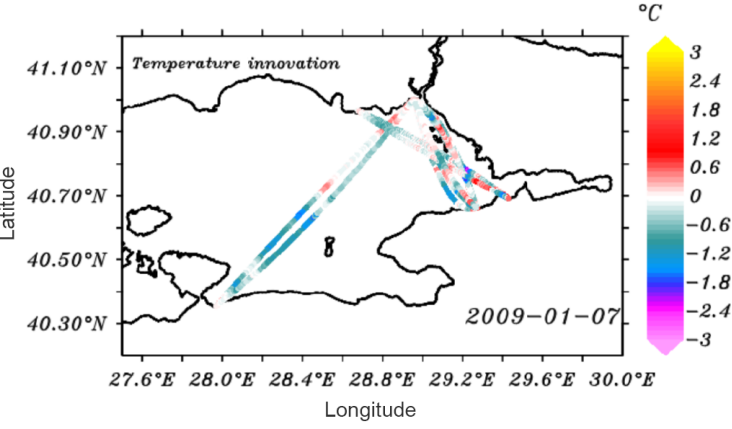

(d)

Figure 9. Horizontal distribution of salinity $(\mathbf{a}, \mathbf{b})$ and temperature $(\mathbf{c}, \mathbf{d})$ innovations along the ferry tracks on 7 January 2009 for FB001 (a, c) and FB002 (b, d). Observations with an innovation out of the range \pm 3 are considered as outliers.

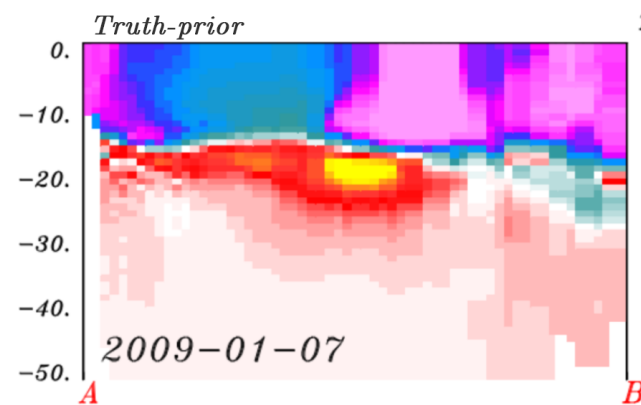

(a)

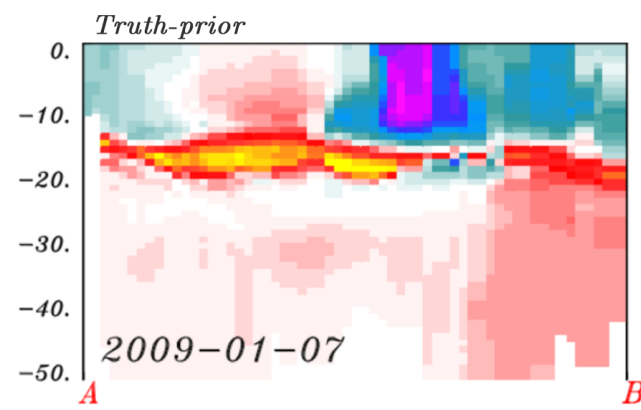

(c)

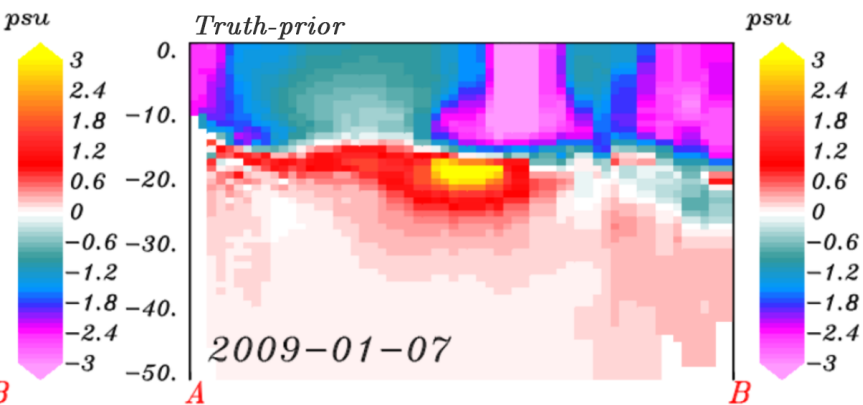

(b)

${ }^{\circ} \mathrm{C}$

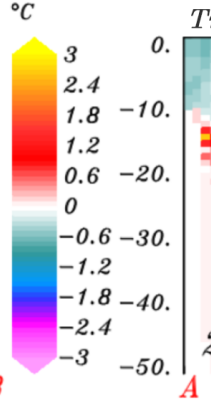

2009-01-07

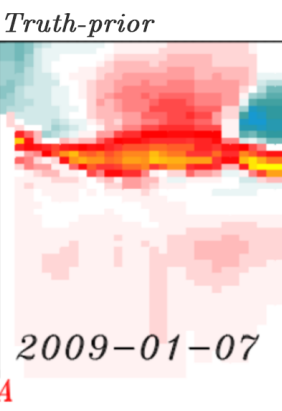

(d)

Figure 10. Vertical distribution of salinity $(\mathbf{a}, \mathbf{b})$ and temperature $(\mathbf{c}, \mathbf{d})$ difference between the NR and the prior ensemble mean along the cross section A-B (see Fig. 5) on 7 January 2009 for FB001 (a, c) and FB002 (b, d). 


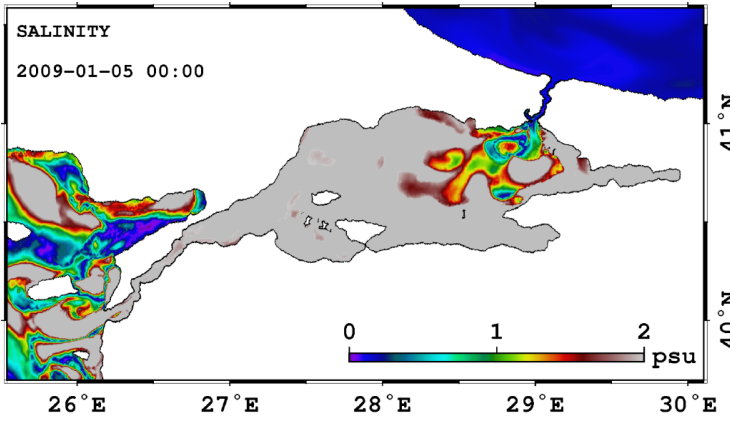

(a)

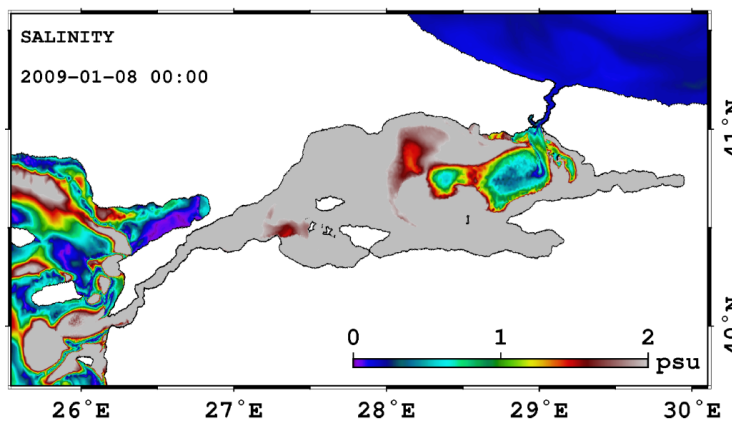

(c)

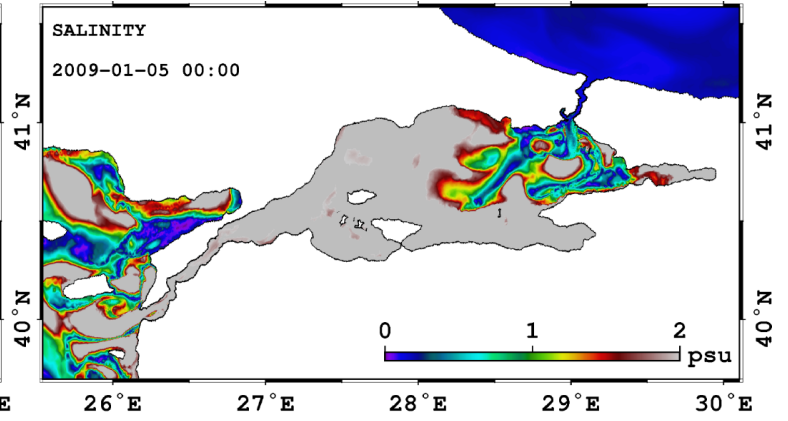

(b)

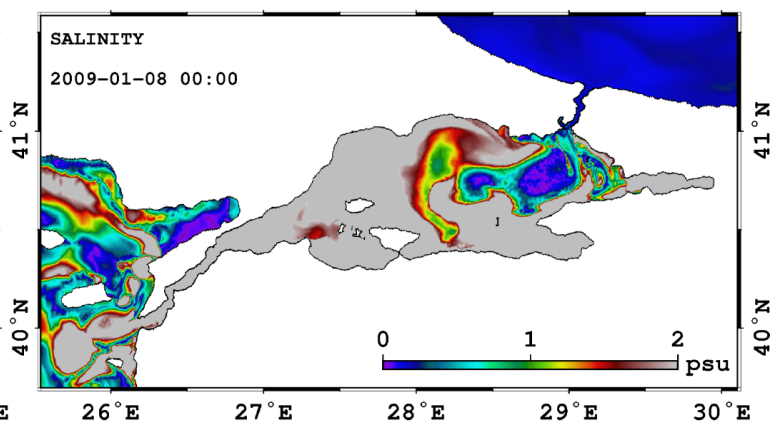

(d)

Figure 11. RMS of the difference between NR and prior ensemble mean salinity at the first $10 \mathrm{~m}$. Comparison of FB001 (a, c) and FB002 (b, d) is shown for 5 January 2009 (a, b) and 8 January 2009 (c, d). RMS of difference is higher than 2 psu in the gray areas.

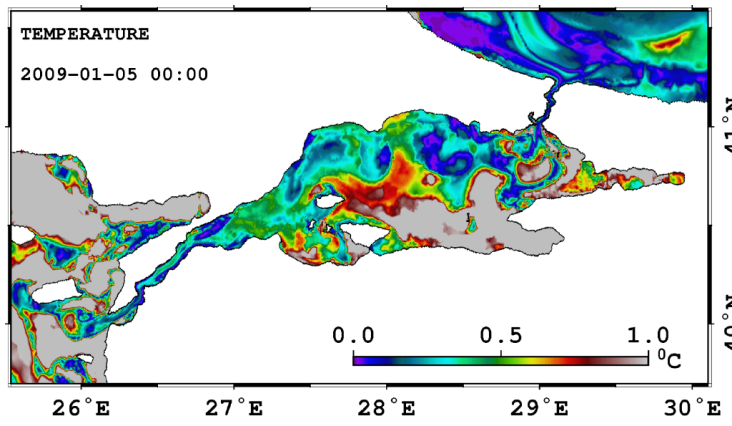

(a)

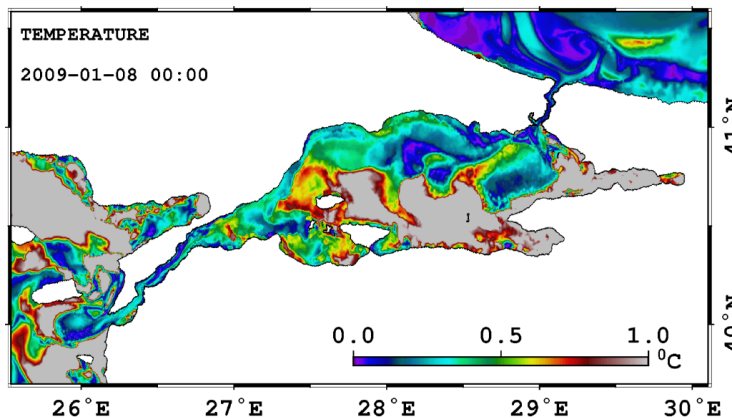

(c)

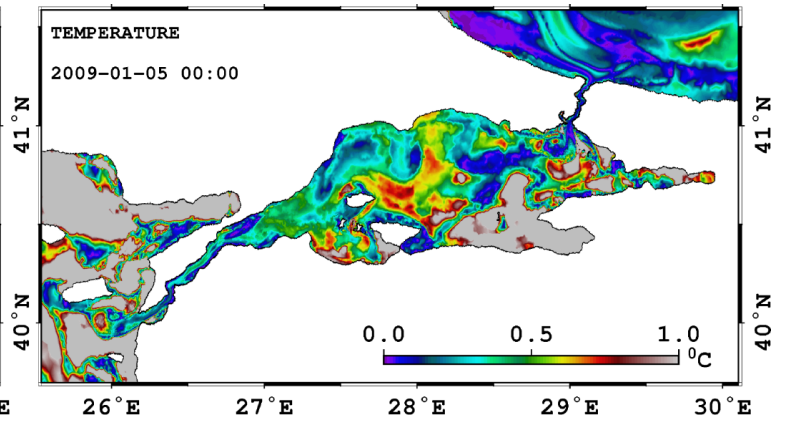

(b)

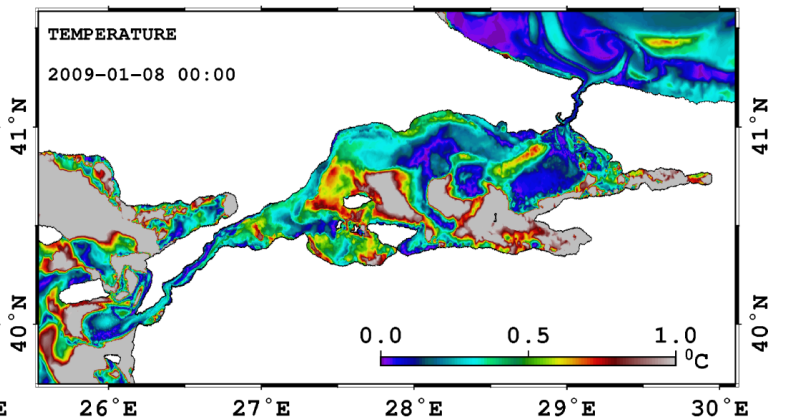

(d)

Figure 12. RMS of the difference between NR and prior temperature at the first $10 \mathrm{~m}$. Comparison of FB001 (a, c) and FB002 (b, d) is shown for 5 January 2009 (a, b) and 8 January 2009 (c, d). RMS of difference is higher than $1^{\circ} \mathrm{C}$ in the gray areas. 


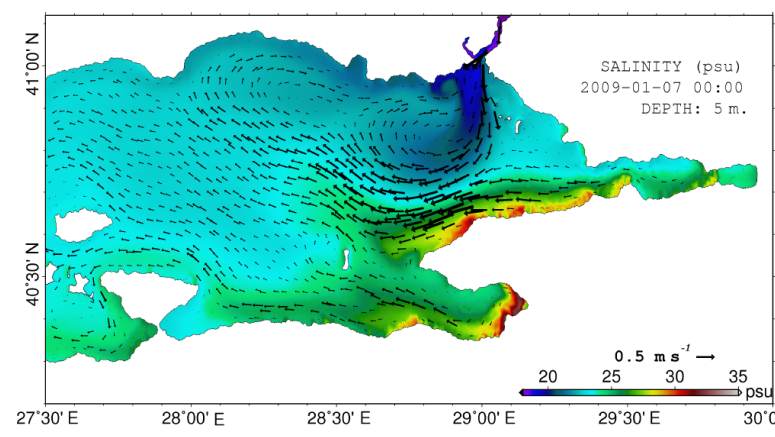

(a)

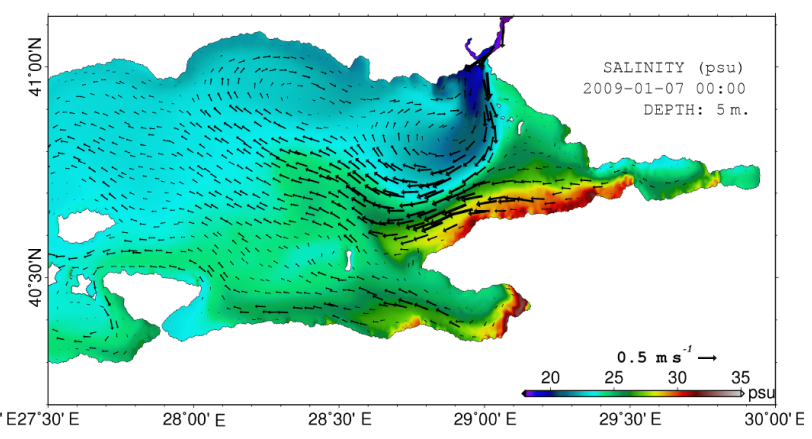

(b)

Figure 13. Salinity overlaid with current fields at $5 \mathrm{~m}$ depth, obtained from experiments (a) FB001 and (b) FB002 on 7 January 2009 at 00:00 UTC.

framework, DART, have been coupled. The implementation of the data assimilation scheme has been reported.

The TSS is an important water passage for the oceanography of the neighboring Black and Aegean seas. It also has important impacts on their ecosystem by maintaining the exchange of water masses and nutrients. The high population in the cities surrounding the TSS and intense marine traffic through the passages add social and economic reasons to monitor the TSS in a sustainable way.

Real observations in the TSS have been obtained by dedicated projects for short time periods or have limited spatial coverage. Moreover, the satellite measurements still have low resolution for monitoring and assimilation purposes. In this study, we proposed a sustainable marine monitoring network using the ferry lines in the eastern Sea of Marmara. We think that equipping the ferries that operate daily everyday from Istanbul to various cities around the Sea of Marmara with temperature and salinity sensors can provide immense amounts of data in both time and space. Given this motivation, we tested a FerryBox network including some of the ferry transects in the basin.

The OSSE methodology has been used to assess the impact of FerryBox measurements. We tried to satisfy the main criteria determined by approximately 40 years of experience of the atmosphere and ocean communities. However, it was still not possible to perform an observing system experiment using real observations to compare with OSSE due to the lack of data during the experiment period.
The results of the two experiments presented here are promising. We showed that the assimilation of the salinity and temperature observations significantly improve the analysis in the Sea of Marmara. The Bosphorus jet has an important role in the propagation of the error reduction towards the western basin where no data are assimilated. Moreover, the Sea of Marmara circulation helps to improve the southern basin, even for short timescales. The lower layer does not show any response to assimilation since a vertical localization around the observations around $5 \mathrm{~m}$ is applied to keep the impact in the upper layer as much as possible. Moreover, the stratification between the upper and lower layers is too strong, so that it prevents the interaction between the two layers. Assimilation of temperature and salinity observations does not alter the circulation in the Sea of Marmara significantly within the experiment period.

In conclusion, the results encourage further data assimilation studies in the Sea of Marmara. The investigations can be extended to different observing systems, different areas of the sea or different dynamical focuses. Moreover, we believe the unique dynamics of the system demonstrated its ability to be a good natural laboratory for future data assimilation studies.

Data availability. The link for the data will be published in the assets tab of this paper when they are made publicly available. 


\section{Appendix A}

The OSSE is performed in a fraternal twin setup as discussed in Sect. 4.1. The nature run (NR) and forward model (FM) are integrated using similar model configurations, but different surface salinity boundary conditions. The NR and FM use the boundary condition (A1a) and (A1b), respectively.

$\left.K_{v} \partial_{z} S\right|_{z=\eta}=\gamma\left(S^{*}-S_{0}\right)-S_{\text {corr }}$

$\left.K_{v} \partial_{z} S\right|_{z=\eta}=S_{0}(E-P-R)+\gamma\left(S^{*}-S_{0}\right)-S_{\text {corr }}^{*}$

In the boundary conditions (A1a) and (A1b), $S_{0}$ and $S^{*}$ are the surface salinity and the reference salinity, respectively, and $\gamma$ is the relaxation coefficient. $S_{\text {corr }}$ and $S_{\text {corr }}^{*}$ are correction terms applied to the salinity corresponding to boundary conditions (A1a) and (A1b), respectively. The correction term is required for mass conservation in a closed lateral boundary model and discussed extensively in Aydoğdu (2017).
In Fig. A1a, the daily time series of the temperature and salinity are presented. The surface mean temperature and salinity show slight variability between 1 and 7 January 2009. The salinity field overlaid with circulation at $5 \mathrm{~m}$ depth on 7 January 2009 at 00:00 UTC is shown in Fig. A1b. Lowsalinity water coming from the Black Sea occupies the area close to the Bosphorus Strait. High salinity near the southern and eastern coasts implies an upwelling of the Mediterranean origin water in the lower layer. The circulation in NR actually favors upwelling and is dominated mainly by westward currents with two anticyclones, one in the northern basin and the other generated by the Bosphorus jet. The NR is more saline compared to the experiments FB001 and FB002 (see Fig. 13), which are performed using the FM. This is because of the water flux term in the surface salinity boundary condition used in FM. However, both model configurations are realistic, as discussed in Aydoğdu (2017).

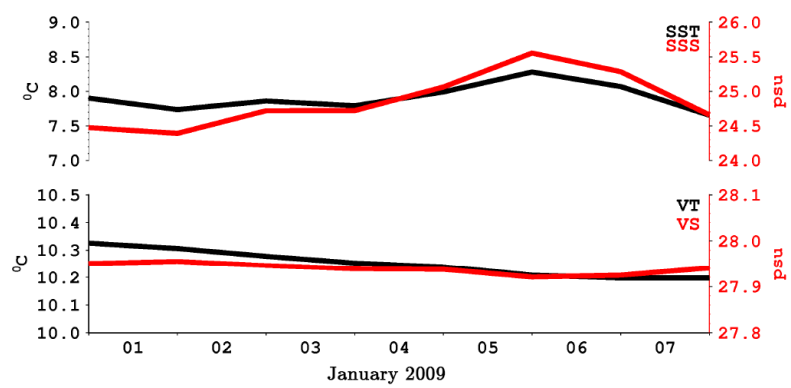

(a)

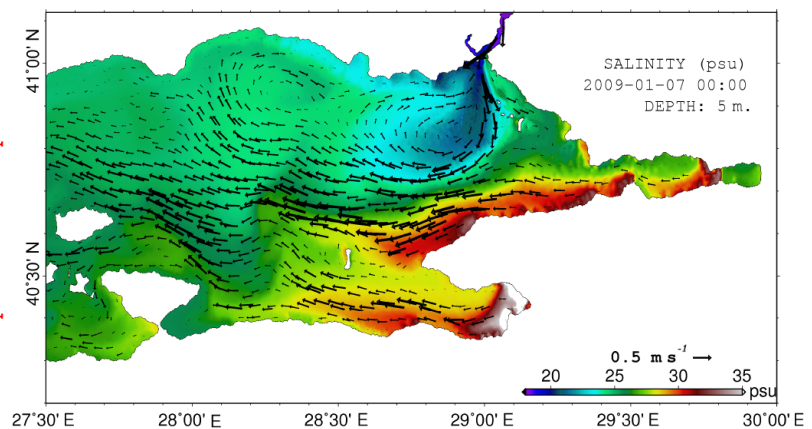

(b)

Figure A1. (a) Daily mean time series of sea surface temperature (SST), sea surface salinity (SSS), volume temperature (VT) and volume salinity (VS) in the Sea of Marmara, obtained from the nature run throughout the experiment period between 1 and 7 January 2009. (b) Salinity overlaid with current fields at $5 \mathrm{~m}$ depth, obtained from nature run on 7 January 2009 at 00:00 UTC. 
Competing interests. The authors declare that they have no conflict of interest.

Special issue statement. This article is part of the special issue "Numerical modeling, predictability and data assimilation in weather, ocean and climate: A special issue honoring the legacy of Anna Trevisan (1946-2016)". It is not associated with a conference.

Acknowledgements. This study is a part of the $\mathrm{PhD}$ thesis of Ali Aydoğdu. He is funded by Ca' Foscari University of Venice and CMCC for his PhD and REDDA project of the Norwegian Research Council for his postdoctoral research period. The National Center for Atmospheric Research (NCAR) is a federally funded research and development center, sponsored by NSF. We are very grateful to the editor and two anonymous referees for helping us to improve the paper substantially.

Edited by: Olivier Talagrand

Reviewed by: two anonymous referees

\section{References}

Altıok, H., Sur, H. İ., and Yüce, H.: Variation of the cold intermediate water in the Black Sea exit of the Strait of Istanbul (Bosphorus) and its transfer through the strait, Oceanologia, 54, 233-254, 2012.

Anderson, J., Hoar, T., Raeder, K., Liu, H., Collins, N., Torn, R., and Avellano, A.: The data assimilation research testbed: A community facility, B. Am. Meteorol. Soc., 90, 1283-1296, 2009.

Anderson, J. L.: An ensemble adjustment Kalman filter for data assimilation, Mon. Weather Rev., 129, 2884-2903, 2001.

Anderson, J. L. and Anderson, S. L.: A Monte Carlo implementation of the nonlinear filtering problem to produce ensemble assimilations and forecasts, Mon. Weather Rev., 127, 2741-2758, 1999.

Arnold Jr., C. P. and Dey, C. H.: Observing-systems simulation experiments: Past, present, and future, B. Am. Meteorol. Soc., 67, 687-695, 1986.

Atlas, R.: Atmospheric observation and experiments to assess their usefulness in data assimilation, J. Meteor. Soc. Jpn, 75, 111-130, 1997.

Aydoğdu, A.: Advanced modeling and data assimilation methods for the design of sustained marine monitoring networks, Ph.D. thesis, Università Ca'Foscari Venezia, 2017.

Aydoğdu, A., Pinardi, N., Pistoia, J., Martinelli, M., Belardinelli, A., and Sparnocchia, S.: Assimilation experiments for the Fishery Observing System in the Adriatic Sea, J. Mar. Syst., 162, 126136, https://doi.org/10.1016/j.jmarsys.2016.03.002, 2016.

Beşiktepe, Ş. T., Sur, H. I., Özsoy, E., Latif, M. A., Oğuz, T., and Ünlüata, Ü.: The circulation and hydrography of the Marmara Sea, Prog. Oceanogr., 34, 285-334, 1994.

Book, J. W., Jarosz, E., Chiggiato, J., and Beşiktepe, Ş.: The oceanic response of the Turkish Straits System to an extreme drop in atmospheric pressure, J. Geophys. Res.-Oceans, 119, 3629-3644, https://doi.org/10.1002/2013JC009480, 2014.
Chiggiato, J., Jarosz, E., Book, J. W., Dykes, J., Torrisi, L., Poulain, P. M., Gerin, R., Horstmann, J., and Beşiktepe, Ş.: Dynamics of the circulation in the Sea of Marmara: Numerical modeling experiments and observations from the Turkish straits system experiment, Ocean Dynam., 62, 139-159, https://doi.org/10.1007/s10236-011-0485-5, 2012.

Danilov, S., Kivman, G., and Schröter, J.: A finite-element ocean model: principles and evaluation, Ocean Modell., 6, 125-150, 2004.

Gaspari, G. and Cohn, S. E.: Construction of correlation functions in two and three dimensions, Q. J. Roy. Meteorol. Soc., 125, $723-$ 757, 1999.

Grayek, S., Staneva, J., Schulz-Stellenfleth, J., Petersen, W., and Stanev, E. V.: Use of FerryBox surface temperature and salinity measurements to improve model based state estimates for the German Bight, J. Mar. Syst., 88, 45-59, https://doi.org/10.1016/j.jmarsys.2011.02.020, 2011.

Gürses, Ö., Aydoğdu, A., Pinardi, N., and Özsoy, E.: A finite element modeling study of the Turkish Straits System, in: The Sea of Marmara - Marine Biodiversity, Fisheries, Conservations and Governance, edited by: Öztürk, B., Çağatay, M. N., Balkis, N., Balkis, N., and Öztürk, B., 169-184, TUDAV Publication, 2016.

Halliwell Jr., G., Srinivasan, A., Kourafalou, V., Yang, H., Willey, D., Le Hénaff, M., and Atlas, R.: Rigorous evaluation of a fraternal twin ocean OSSE system for the Open Gulf of Mexico, J. Atmos. Ocean. Tech., 31, 105-130, 2014.

Halliwell Jr., G., Kourafalou, V., Le Hénaff, M., Shay, L., and Atlas, R.: OSSE impact analysis of airborne ocean surveys for improving upper-ocean dynamical and thermodynamical forecasts in the Gulf of Mexico, Prog. Oceanogr., 130, 32-46, https://doi.org/10.1016/j.pocean.2014.09.004, 2015.

Hoteit, I., Hoar, T., Gopalakrishnan, G., Collins, N., Anderson, J., Cornuelle, B., Köhl, A., and Heimbach, P.: A MITgcm/DART ensemble analysis and prediction system with application to the Gulf of Mexico, Dynam. Atmos. Ocean., 63, 1-23, 2013.

Houtekamer, P. L. and Mitchell, H. L.: Data assimilation using an ensemble Kalman filter technique, Mon. Weather Rev., 126, 796$811,1998$.

Huang, R. X.: Real Freshwater Flux as a Natural Boundary Condition for the Salinity Balance and Thermohaline Circulation Forced by Evaporation and Precipitation, J. Phys. Oceanogr., 23, 2428-2446, https://doi.org/10.1175/15200485(1993)023<2428:RFFAAN>2.0.CO;2, 1993.

Hüsrevoğlu, S.: Modeling Of The Dardanelles Strait Lower-layer Flow Into The Marmara Sea, Master's thesis, Institute of Marine Sciences, METU, 1998.

Jarosz, E., Teague, W. J., Book, J. W., and Beşiktepe, S.: On flow variability in the Bosphorus Strait, J. Geophys. Res.-Oceans (1978-2012), 116, C08038, https://doi.org/10.1029/2010JC006861, 2011.

Jarosz, E., Teague, W. J., Book, J. W., and Beşiktepe, Ş.: Observations on the characteristics of the exchange flow in the Dardanelles Strait, J. Geophys. Res.-Oceans, 117, c11012, https://doi.org/10.1029/2012JC008348, 2012.

Karspeck, A. R., Yeager, S., Danabasoglu, G., Hoar, T., Collins, N., Raeder, K., Anderson, J., and Tribbia, J.: An Ensemble Adjustment Kalman Filter for the CCSM4 Ocean Component, J. Climate, 26, 7392-7413, https://doi.org/10.1175/JCLI-D-12$00402.1,2013$. 
Korres, G., Ntoumas, M., Potiris, M., and Petihakis, G.: Assimilating Ferry Box data into the Aegean Sea model, J. Mar. Syst., 140, 59-72, https://doi.org/10.1016/j.jmarsys.2014.03.013, 2014.

Masutani, M., Schlatter, T. W., Errico, R. M., Stoffelen, A., Andersson, E., Lahoz, W., Woollen, J. S., Emmitt, G. D., Riishøjgaard, L.-P., and Lord, S. J.: Observing system simulation experiments, in: Data Assimilation, 647-679, Springer, 2010.

Özsoy, E., Di Iorio, D., Gregg, M. C., and Backhaus, J. O.: Mixing in the Bosphorus Strait and the Black Sea continental shelf: observations and a model of the dense water outflow, J. Mar. Syst., 31, 99-135, 2001.

Petersen, W.: FerryBox systems: State-of-the-art in Europe and future development, J. Mar. Syst., 140, Part A, 4-12, https://doi.org/10.1016/j.jmarsys.2014.07.003, 2014.

Raeder, K., Anderson, J. L., Collins, N., Hoar, T. J., Kay, J. E., Lauritzen, P. H., and Pincus, R.: DART/CAM: An Ensemble Data Assimilation System for CESM Atmospheric Models, J. Climate, 25, 6304-6317, https://doi.org/10.1175/JCLI-D-11$00395.1,2012$.

Sannino, G., Sözer, A., and Özsoy, E.: A high-resolution modelling study of the Turkish Straits System, Ocean Dynam., 67, 397-432, https://doi.org/10.1007/s10236-017-1039-2, 2017.

Schwartz, C. S., Romine, G. S., Sobash, R. A., Fossell, K. R., and Weisman, M. L.: NCAR's Experimental Real-Time ConvectionAllowing Ensemble Prediction System, Weather Forecast., 30, 1645-1654, https://doi.org/10.1175/WAF-D-15-0103.1, 2015.
Seppälä, J., Ylöstalo, P., Kaitala, S., Hällfors, S., Raateoja, M., and Maunula, P.: Ship-of-opportunity based phycocyanin fluorescence monitoring of the filamentous cyanobacteria bloom dynamics in the Baltic Sea, Estuarine, Coast. Shelf Sci., 73, 489500, https://doi.org/10.1016/j.ecss.2007.02.015, 2007.

Sørensen, K., Grung, M., and Röttgers, R.: An intercomparison of in vitro chlorophyll a determinations for MERIS level 2 data validation, Int. J. Remote Sens., 28, 537-554, https://doi.org/10.1080/01431160600815533, 2007.

Sözer, A. and Özsoy, E.: Modeling of the Bosphorus exchange flow dynamics, Ocean Dynam., 1-23, https://doi.org/10.1007/s10236016-1026-z, 2017.

Stanev, E. V., Grashorn, S., and Zhang, Y. J.: Cascading ocean basins: numerical simulations of the circulation and interbasin exchange in the Azov-Black-Marmara-Mediterranean Seas system, Ocean Dynam., 1-23, 2017.

Tuğrul, S., Beşiktepe, T., and Salihoğlu, I.: Nutrient exchange fluxes between the Aegean and Black Seas through the Marmara Sea, Mediterranean Marine Science, 3, 33-42, 2002.

Ünlüata, Ü., Oğuz, T., Latif, M., and Özsoy, E.: On the physical oceanography of the Turkish Straits, in: The physical oceanography of sea straits, 25-60, Springer, 1990.

Wang, Q., Danilov, S., and Schröter, J.: Finite element ocean circulation model based on triangular prismatic elements, with application in studying the effect of topography representation, J. Geophys. Res.-Oceans (1978-2012), 113, C05015, https://doi.org/10.1029/2007JC004482, 2008. 